\title{
Commentary: The koniocellular whiteboard
}

\section{Paul R. Martin ${ }^{1,2,3 *}$ and Samuel G. Solomon ${ }^{4}$}

${ }^{1}$ Save Sight Institute and Department of Clinical Ophthalmology, The University of Sydney, Sydney, NSW 2000, Australia

${ }^{2}$ Australian Research Council Centre of Excellence for Integrative Brain Function, The University of Sydney, Sydney, NSW 2000, Australia

${ }^{3}$ School of Medical Sciences, The University of Sydney, Sydney, NSW 2000, Australia

${ }^{4}$ Department of Experimental Psychology, University College London, WC1P 0AH, London, England

Abbreviated title: K-cell whiteboard

Special Issue Editor: Jon Kaas

*Corresponding author: Paul Martin, Save Sight Institute, 8 Macquarie Street, Sydney, NSW 2000, Australia. Email: prmartin@physiol.usyd.edu.au

This article has been accepted for publication and undergone full peer review but has not been through the copyediting, typesetting, pagination and proofreading process which may lead to differences between this version and the Version of Record. Please cite this article as an 'Accepted Article', doi: 10.1002/cne.24426 (C) 2018 Wiley Periodicals, Inc.

Received: J an 08, 2018; Accepted: F eb 27, 2018 


\section{Abstract}

In 1994 Vivien Casagrande published a review paper in which she summarised evidence for a koniocellular pathway to visual cortex. Here we try to explain how that review moved the field forward, and summarise some key unanswered questions about koniocellular pathways.

\section{Commentary}

In February 2012 Vivien Casagrande visited the Queensland rain forest to attend the "Vision Down Under" symposium, presenting then unpublished and important results showing that the pulvinar plays a major role in regulating activity levels in primary visual cortex (Purushothaman, Marion, Li, \& Casagrande, 2012). Vivien and husband James (Mac) McKanna then drove from Queensland to our visit our laboratories in Sydney. We spent four pleasant days discussing science and life, and enjoying Mac's fine baritone singing. The afternoons were devoted to planning a "New Review of Koniocellular Pathways"; our goal was to assess progress since Vivien's groundbreaking review of the topic 20 years earlier (Casagrande, 1994). We made notes on an office whiteboard, which has miraculously remained un-erased. There is enough material there to stoke more than one review and inspire many new experiments, but now we will need to do it without Vivien.

The purpose of the 1994 review was to challenge the accepted wisdom that thalamocortical pathways in the primate comprise only two afferent channels - parvocelluar (P) and magnocellular (M). By assembling extensive anatomical, neurochemical, and functional data she showed that in addition to these two channels, there was a third, konicellular (K), pathway from retina to visual cortex, passing through the (koniocellular / interlaminar) regions of the lateral geniculate nucleus (Figure 1). The K-cells, she showed, form a clear and consistent third cortical afferent stream, with direct access to the 
supragranular cortical layers including cytochrome-rich blob regions of primary visual cortex, across all primate species studied to that time. The review made clear that the K-cell layers were not simply interneurons, nor a vestigial remnant, and that they could provide distinct contributions to image-forming vision. But the review also made clear that K-cells likely comprise more than one functional subgroup, and raised the possibility that different types of $\mathrm{K}$ cells play distinct and specialised roles in visual processing. The question can now be posed: how are K-cells of one kind, and how are they of many kinds? Let's put that more simply: how can I tell if I'm a K-cell?

Anatomically, K-cells are defined by uniform expression of neurochemical markers such as calbindin and preferential projection to superficial layers of primary and association visual areas (Hendry \& Yoshioka, 1994) But physiologically, K-cells are defined by their heterogeneity. Some K-cells (for example, blue-on cells and suppressed-by-contrast cells) have a very clear and unique functional signatures (Roy et al., 2009; Tailby et al., 2007). But others do not, and many K-cells are almost completely unresponsive to visual stimuli (White, Solomon, \& Martin, 2001; Xu et al., 2001). As we learn more about the physiological properties of K-cells, the big question arises whether we should continue to "lump" these populations or start to "split" them.

Since Vivien's 1994 review our field of study has gained new and detailed knowledge about K-cell pathways. But each new discovery raises new and difficult questions. We have learned that there is a substantial direct K-cell projection to extrastriate motion-processing area MT (Sincich, Park, Wohlgemuth, \& Horton, 2004), and that blindsight depends on the geniculate (implicating this pathway; Schmid et al., 2010) but the functional properties of the K-cells driving MT, and the importance of this pathway for normal vision remain unknown. We have confirmed that activating K-cells causes direct activation of supragranular layers of V1 (Chatterjee \& Callaway, 2003; Klein et al., 2016), and that K-cells are selectively linked 
to slow changes in cortical activity (Cheong, Tailby, Martin, Levitt, \& Solomon, 2011; Pietersen et al., 2017). These observations that are consistent with proposals that K-cell activity could act to regulate cortical activity originating $\mathrm{P}$ and $\mathrm{M}$ pathways (Casagrande, 1994; Jones, 2001), but we still do not know whether one, some, or all K-cell sub-populations are involved.

We continue to find parallels in structure and function between K-cells and the "nonstandard / W" populations previously identified in cat retina and lateral geniculate nucleus (Cleland, Levick, Morstyn, \& Wagner, 1976; Hoffmann, Stone, \& Sherman, 1972). Like Wcells in cat, the K-cells originate from diverse ganglion cell populations and supply multiple low-acuity signals in parallel to the cortex (Figure 2). But whether the numerical dominance of high-acuity $\mathrm{X} / \mathrm{Y}$ pathways in cats and $\mathrm{P} / \mathrm{M}$ pathways in primates implies anything but highacuity detection of species-specific survival clues (mice for cats? fruit for monkeys?), and where other homologies lie between rodent, carnivore and primate visual systems are stubborn unsolved questions that have persisted for over 30 years. We have made much progress and much more needs to be done. The whiteboard stands for us as testimony to Vivien's enthusiasm, acumen, and enormously generous scientific spirit. We miss her.

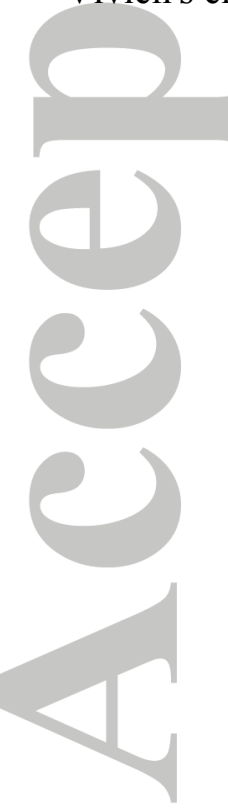




\section{References}

Casagrande, V. A. (1994). A third parallel visual pathway to primate area V1. Trends in Neurosciences, 17(7), 305-310.

Chatterjee, S., \& Callaway, E. M. (2003). Parallel colour-opponent pathways to primary visual cortex. Nature, 426, 668-671.

Cheong, S. K., Tailby, C., Martin, P. R., Levitt, J. B., \& Solomon, S. G. (2011). Slow intrinsic rhythm in the koniocellular visual pathway. Proceedings of the National Academy of Sciences of the USA, 108(35), 14659-14663.

Cleland, B. G., Levick, W. R., Morstyn, R., \& Wagner, H. G. (1976). Lateral geniculate relay of slowly-conducting retinal afferents to cat visual cortex. Journal of Physiology, 255, 299-320.

Hendry, S. H. C., \& Yoshioka, T. (1994). A neurochemically distinct third channel in the macaque dorsal lateral geniculate nucleus. Science, 264, 575-577.

Hoffmann, K.-P., Stone, J., \& Sherman, S. M. (1972). Relay of receptive-field properties in dorsal lateral geniculate nucleus of the cat. Journal of Neurophysiology, 35, 518-531.

Jones, E. G. (2001). The thalamic matrix and thalamocortical synchrony. Trends in Neurosciences, 24(10), 595-601.

Klein, C., Evrard, H. C., Shapcott, K. A., Haverkamp, S., Logothetis, N. K., \& Schmid, M. C. (2016). Cell-Targeted Optogenetics and Electrical Microstimulation Reveal the Primate Koniocellular Projection to Supra-granular Visual Cortex. Neuron, 90(1), 143151. 
Pietersen, A. N. J., Cheong, S. K., Munn, B., Gong, P., Martin, P. R., \& Solomon, S. G. (2017). Relationship between cortical state and spiking activity in the lateral geniculate nucleus of marmosets. Journal of Physiology, 595(13), 4475-4492.

Purushothaman, G., Marion, R., Li, K., \& Casagrande, V. A. (2012). Gating and control of primary visual cortex by pulvinar. Nature Neuroscience, 115(6), 905-912.

Roy, S., Martin, P. R., Dreher, B., Saalmann, Y. B., Hu, D., \& Vidyasagar, T. R. (2009). Segregation of short-wavelength sensitive (S) cone signals in the macaque dorsal lateral geniculate nucleus. European Journal of Neuroscience, 30(8), 1517-1526.

Schmid, M. C., Mrowka, S. W., Turchi, J., Saunders, R. C., Wilke, M., Peters, A. J., [ ] Leopold, D. A. (2010). Blindsight depends on the lateral geniculate nucleus. Nature, 466(7304), 373-377.

Sincich, L. C., Park, K. F., Wohlgemuth, M. J., \& Horton, J. C. (2004). Bypassing V1: a direct geniculate input to area MT. Nature Neuroscience, 7, 1123-1128.

Tailby, C., Solomon, S. G., Dhruv, N. T., Majaj, N. J., Sokol, S. H., \& Lennie, P. (2007). A new code for contrast in the primate visual pathway. Journal of Neuroscience, 27, 39043909.

White, A. J. R., Solomon, S. G., \& Martin, P. R. (2001). Spatial properties of koniocellular cells in the lateral geniculate nucleus of the marmoset Callithrix jacchus. Journal of Physiology, 533(Pt 2), 519-535.

Xu, X., Ichida, J. M., Allison, J. D., Boyd, J. D., Bonds, A. B., \& Casagrande, V. A. (2001). A comparison of koniocellular, magnocellular and parvocellular receptive field properties in the lateral geniculate nucleus of the owl monkey (Aotus trivirgatus). Journal of

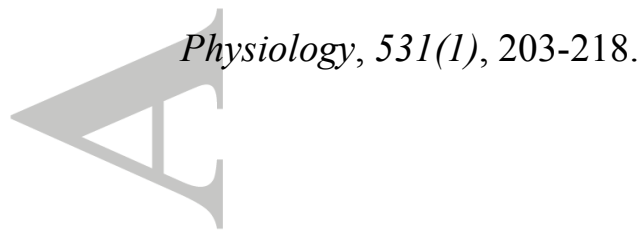




\section{Figure Legends}

Figure 1. Simplified schematic after Casagrande (1994, Fig. 1) showing subcortical and cortical connections of Koniocellular (K), Magnocellular (M), and Parvocellular (P) pathways. The main points to be made at that time were 1) the projection of $\mathrm{K}$ pathways to primary visual cortex, 2) the direct acess of some K pathways to superficial layers of primary visual cortex and the cytochrome oxidase-rich 'blobs' in supragranular layers, and 3) the selective interaction of K pathways with attention-regulating centers such as superior colliculus.

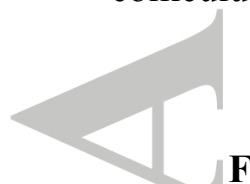

Figure 2. Sampling of visual space by ganglion cells. a, Each panel shows a schematic mosaic of sampling units (ganglion cells / receptive fields). Upper row: Parvocellular (P) cells. In central visual field (left column) the P cell mosaic has smallest sampling unit size and correspondingly highest acuity. Sampling unit size rises and acuity fall dramatically in the peripheral visual field. Centre row: Magnocellular (M) cells. Acuity drops on passing from central to peripheral visual field; note that $\mathrm{M}$ cell acuity in central visual field is comparable to $\mathrm{P}$ cell acuity in the periphery. Lower row: Koniocellular (K) cells. Multiple populations of K cells (indicated by distinct size and shape of symbols) are present at low numbers in the central visual field, but $\mathrm{K}$ cells acuity approaches that of $\mathrm{P}$ and $\mathrm{M}$ cells in the periphery. $\mathrm{b}$. Comparison of cat and monkey cell populations. The $\mathrm{P}, \mathrm{M}$ and $\mathrm{K}$ populations in monkeys occupy the same relative positions as $\mathrm{X}, \mathrm{Y}$ and $\mathrm{W}$ populations in cats, but at approximately five-fold higher sampling density. Axis values are estimated from behavioural, receptive field, and cell density measurements. The values are subject to many assumptions, of course, but we hope that the reader gets our message. 
Figure 3. The whiteboard. A transcription of the text is available on request to the authors.
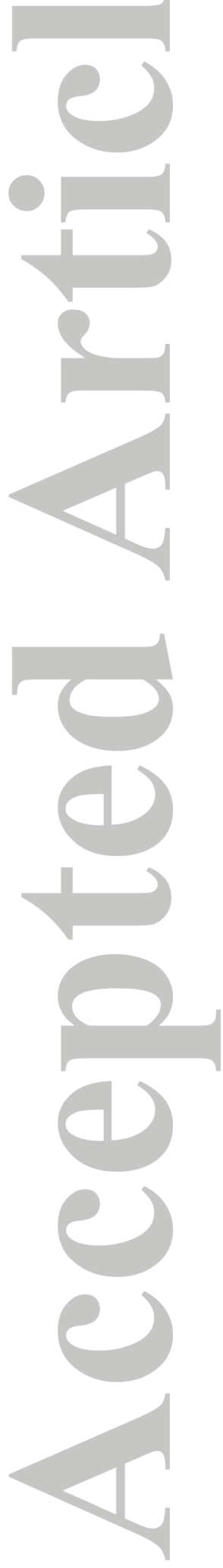

John Wiley \& Sons

This article is protected by copyright. All rights reserved. 


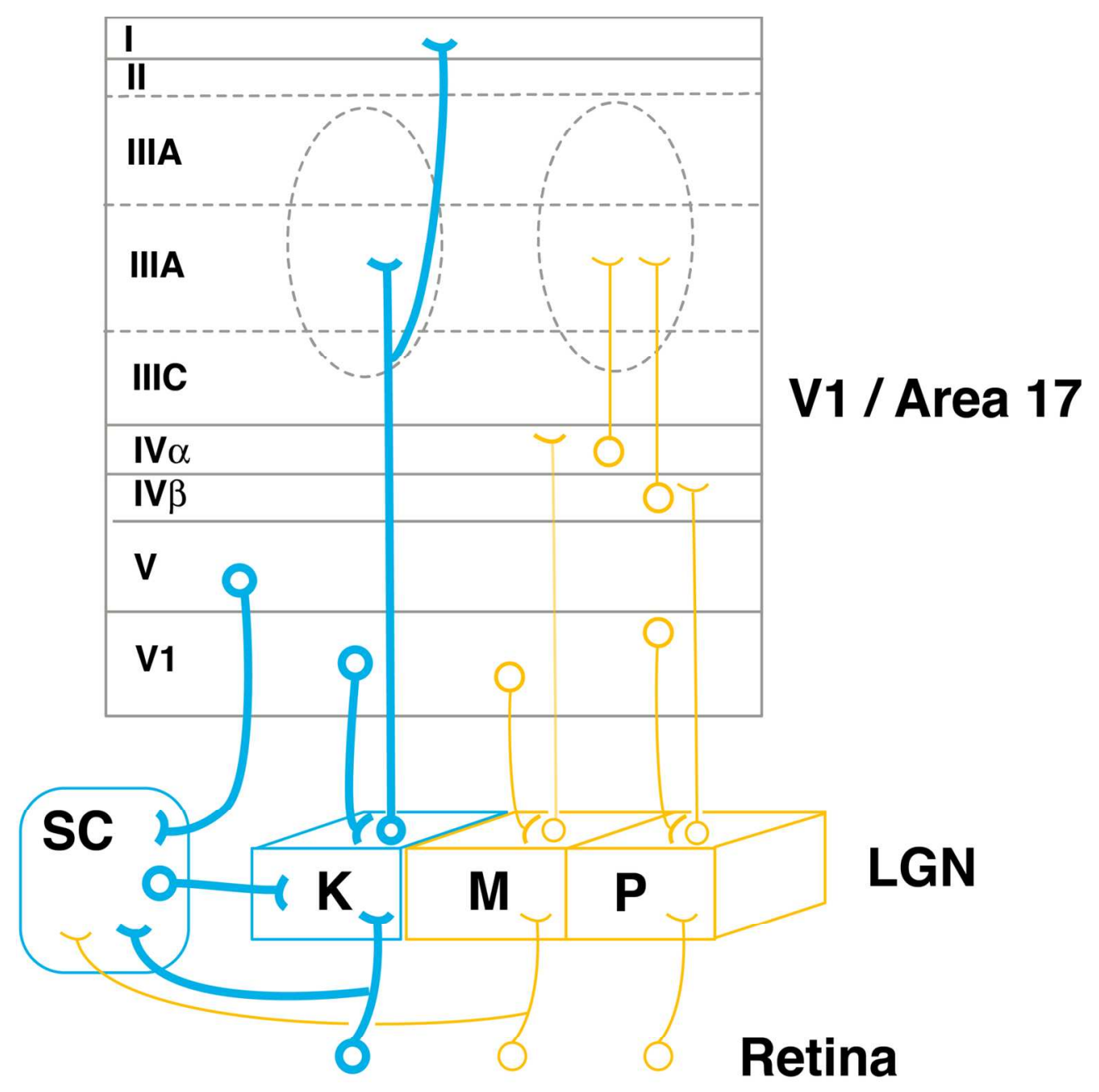

Figure 1. Simplified schematic after Casagrande (1994, Fig. 1) showing subcortical and cortical connections of Koniocellular (K), Magnocellular (M), and Parvocellular (P) pathways. The main points to be made at that time were 1 ) the projection of $\mathrm{K}$ pathways to primary visual cortex, 2) the direct acess of some $\mathrm{K}$ pathways to superficial layers of primary visual cortex and the cytochrome oxidase-rich 'blobs' in supragranular layers, and 3 ) the selective interaction of $\mathrm{K}$ pathways with attention-regulating centers such as superior colliculus.

$145 \times 151 \mathrm{~mm}(300 \times 300 \mathrm{DPI})$

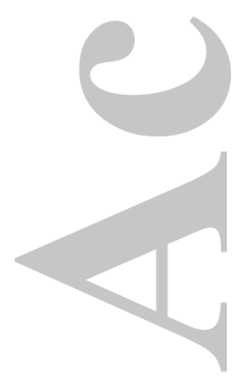


a
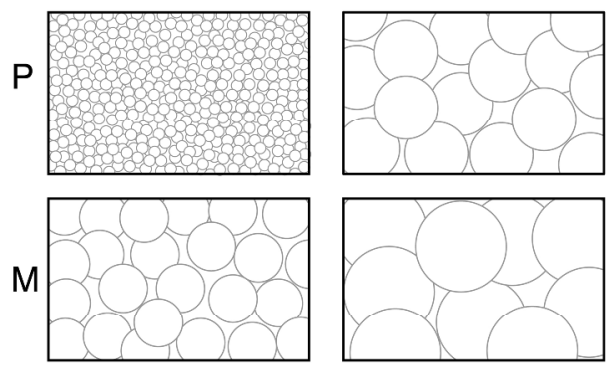

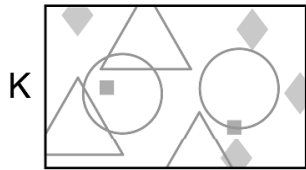

Central Visual Field

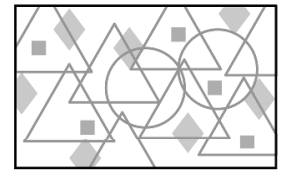

Peripheral

Visual Field

b
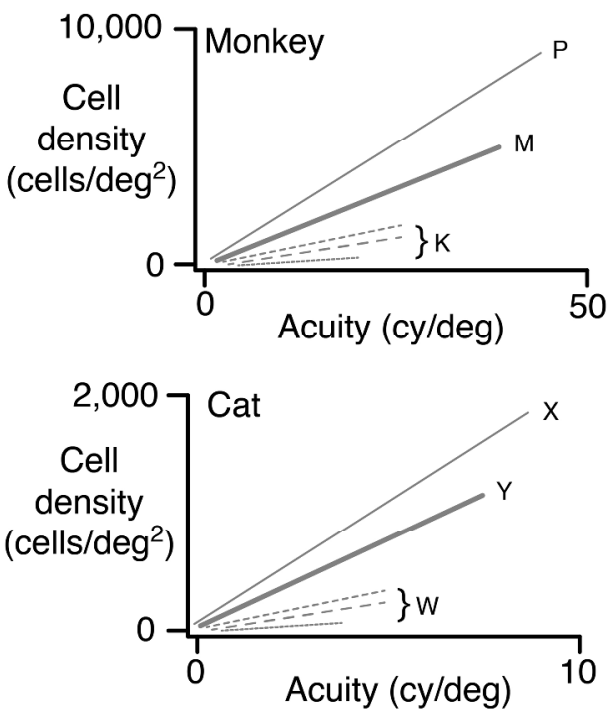

Figure 2. Sampling of visual space by ganglion cells. a, Each panel shows a schematic mosaic of sampling units (ganglion cells / receptive fields). Upper row: Parvocellular (P) cells. In central visual field (left column) the P cell mosaic has smallest sampling unit size and correspondingly highest acuity. Sampling unit size rises and acuity fall dramatically in the peripheral visual field. Centre row: Magnocellular (M) cells.

Acuity drops on passing from central to peripheral visual field; note that $M$ cell acuity in central visual field is comparable to $\mathrm{P}$ cell acuity in the periphery. Lower row: Koniocellular (K) cells. Multiple populations of $\mathrm{K}$ cells (indicated by distinct size and shape of symbols) are present at low numbers in the central visual field, but $K$ cells acuity approaches that of $P$ and $M$ cells in the periphery. $b$. Comparison of cat and monkey cell populations. The $\mathrm{P}, \mathrm{M}$ and $\mathrm{K}$ populations in monkeys occupy the same relative positions as $\mathrm{X}, \mathrm{Y}$ and $\mathrm{W}$ populations in cats, but at approximately five-fold higher sampling density. Axis values are estimated from behavioural, receptive field, and cell density measurements. The values are subject to many assumptions, of course, but we hope that the reader gets our message. 


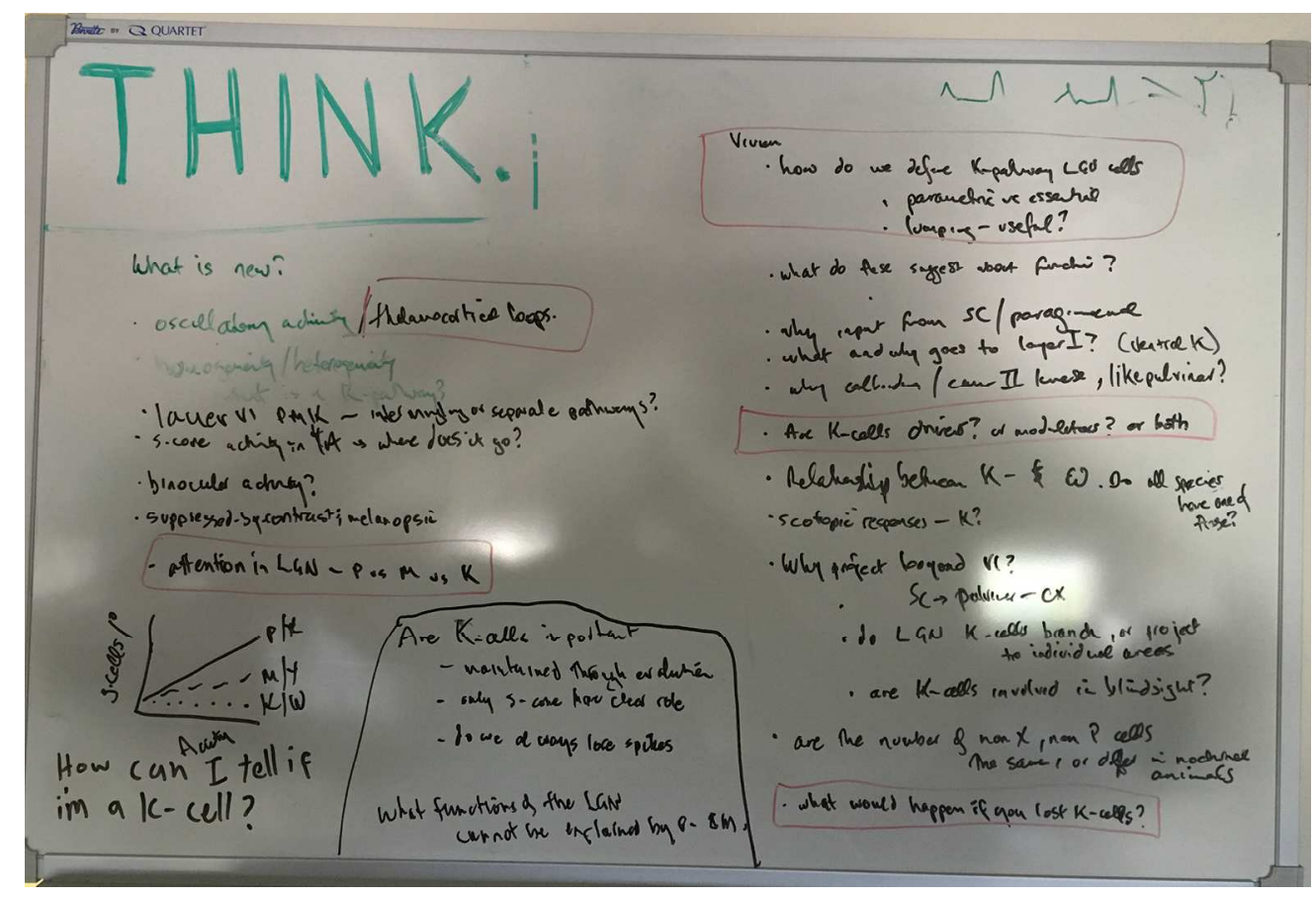

Figure 3. The whiteboard. A transcription of the text is available on request to the authors. $169 \times 114 \mathrm{~mm}(300 \times 300 \mathrm{DPI})$

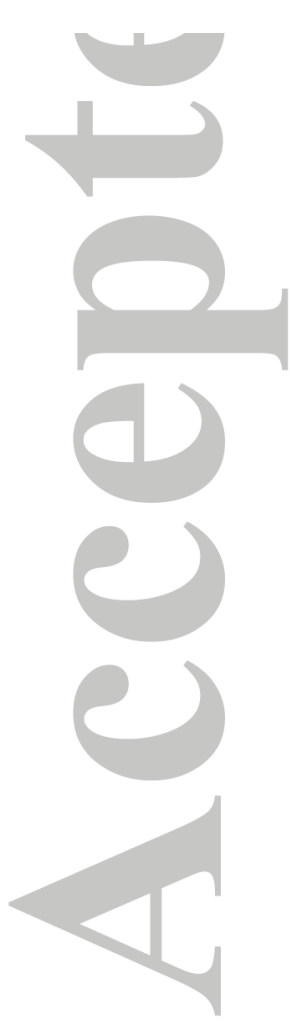

